\title{
La piel en la cocina
}

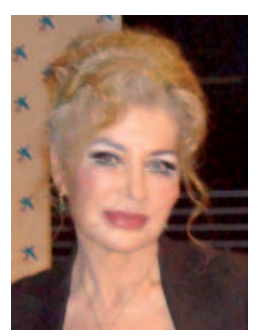

Aurora Guerra Tapia Jefa de Sección de Dermatología. Hospital Universitario 12 de Octubre. Madrid. Profesora titular de Dermatología. Universidad Complutense de Madrid.

Ese cutis amasado con aceituna y jazmín.

Federico García Lorca

(1898-1936)

En este anhelo intelectual —o tal vez anacrónica cruzada- de encontrar la relación de la dermatología con el arte (aunque sea de forma tangente, oblicua, apenas un beso de mariposa), he ganado algunas batallas.

Encontré suficiente justificación para este empeño en la obra de Cervantes El ingenioso hidalgo don Quijote de la Mancha ${ }^{1}$, plena de bellísimas y aleccionadoras referencias acerca de la piel sana o enferma. Jugué con esa muestra del saber y arte popular que representan los refranes². Inventé el término tricocosmetomanía y se lo brindé a Sissi emperatriz por su dismórfica consagración al cabello y a los cosméticos ${ }^{3}$. No olvidé la poesía y, de entre todos los poetas, fue imprescindible Pablo Neruda: «Debajo de tu piel, vive la luna» ${ }^{4}$. Me acerqué al cine, émulo de la vida, con Stigmata y el reflejo sangriento de su dañada mente en su piel ${ }^{5}$. Los verdes frutos de la naturaleza paseados por el órgano cutáneo me descubrieron que, como en las virtudes y los defectos, el veneno está en la dosis $^{6}$. El teatro me mostró a La cantante calva en todo su impudor ${ }^{7}$. Y escuché la desafinada sífilis de Schubert sobre su piel, vestida de melodías incomparables ${ }^{8}$. También el folclore de las Fallas de Valencia ${ }^{9}$ o los pelirrojos inmortalizados por los prerrafaelitas ${ }^{10}$, así como la mitología mirando al sol ${ }^{11}$ y a Narciso ${ }^{12}$ supieron hablarme de la piel. E incluso me atreví con el latín de la rosa rosae reflejada en el cutis ${ }^{13}$ y con la novela corta de la piel de cristal del licenciado Vidriera ${ }^{14}$.

Pero hoy el beso de la mariposa se ha apartado de museos, bibliotecas, auditorios y salones, y se ha acercado a la cocina.

Y mucho más temeraria que audaz, he recapacitado sobre si el llamado arte gastronómico, efímero por definición, pero con pretensiones de nobleza, tendría un punto de encuentro con la dermatología.

Encontré que podría decir que la piel guisa sus procesos patológicos, alegando la metáfora hirviente de las bullas del eccema - cocer-, o la figura del asado a fuego lento de la poiquilodermia solar. Pero no lo haré.

He preferido dedicarme a los cimientos, a la materia prima, a los alimentos: sustancias que, introducidas en el organismo, son utilizadas por este para la producción de energía o para la reparación, el mantenimiento y el desarrollo de la estructura de sus células y tejidos. 
Y hete aquí que me he topado con un menú heterodoxo que contenía los siguientes epígrafes:

- Mancha en vino de Oporto: nevo flámeo (fig. 1).

- Molusco: molluscum contagiosum.

- Lesiones en forma de lenteja: lentigos.

- Dedos en salchicha: enfermedades autoinmunitarias del tejido conectivo (fig. 2).

- Lunar en forma de huevo frito: nevo melanocítico displásico (fig. 3).

- Lesión ampollosa con distribución de huevo frito: dermatosis por inmunoglobulina A (IgA) lineal.

- Placa rupiácea (de concha de ostra): psoriasis.

- Verruga en forma de coliflor: condiloma acuminado (fig. 4).

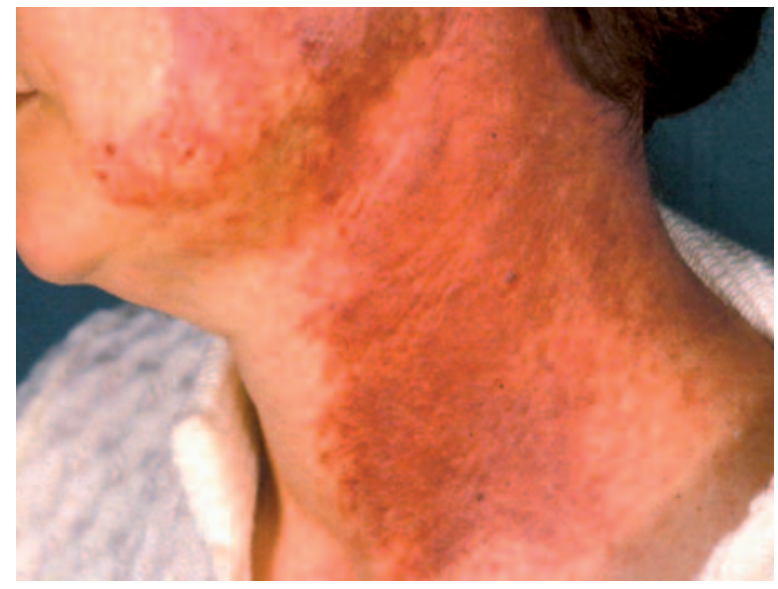

Figura 1. Nevo flámeo: mancha en vino de Oporto.

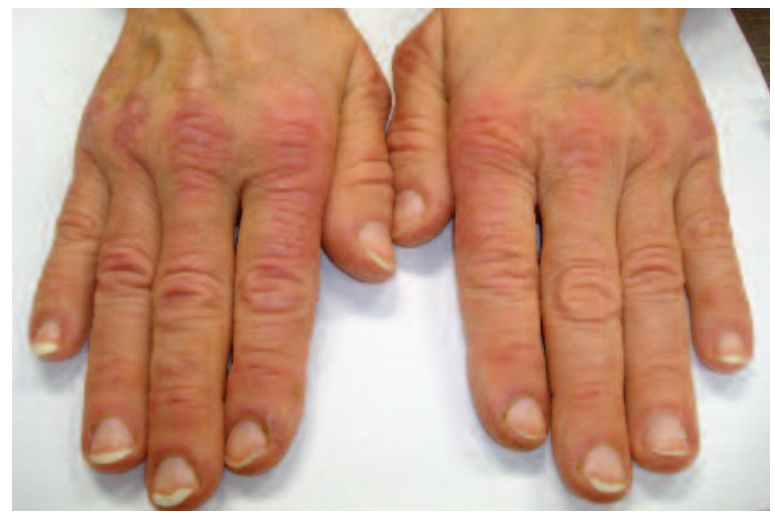

Figura 2. Dermatomiositis: dedos con aspecto de salchichas.
- Lesión en forma de cresta de gallo: condiloma acuminado.

- Lesiones múltiples como semillas de higo en la cara: sicosis (de sico, higo).

- Lesión de color ajamonado: chancro sifilítico.

- Lesión de color jalea de manzana: lupoma tuberculoso.

- Callo llamado en ojo de gallo: heloma (fig. 5).

- Piel de naranja: erisipela, carcinoma inflamatorio de mama.

Y muchos más. Pero no explicaré cada diagnóstico. No es hoy mi objetivo. Solo pretendo que, cuando su dermatólogo les hable de alimentos mientras mira su piel, no piensen que está loco.

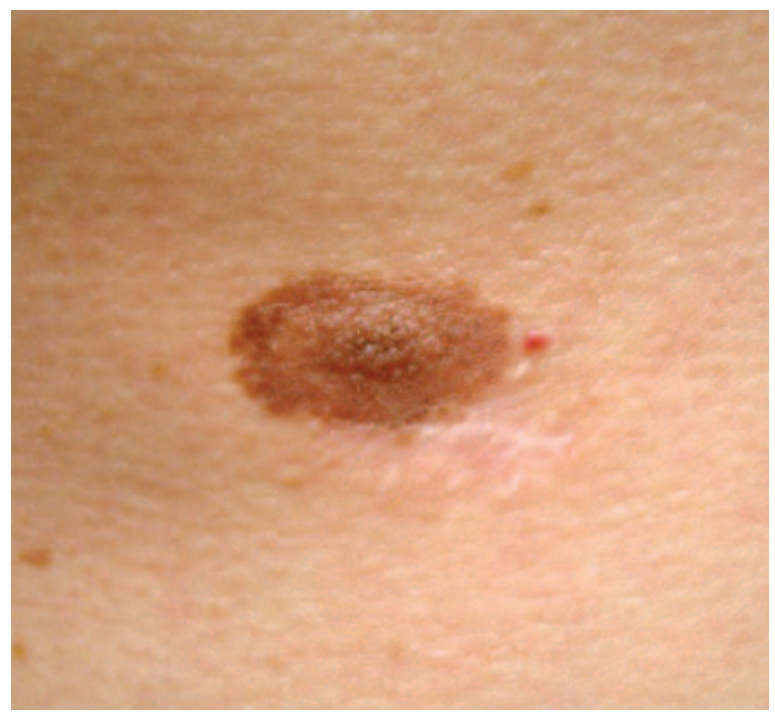

Figura 3. Nevo melanocítico displásico: lesión en forma de huevo frito.

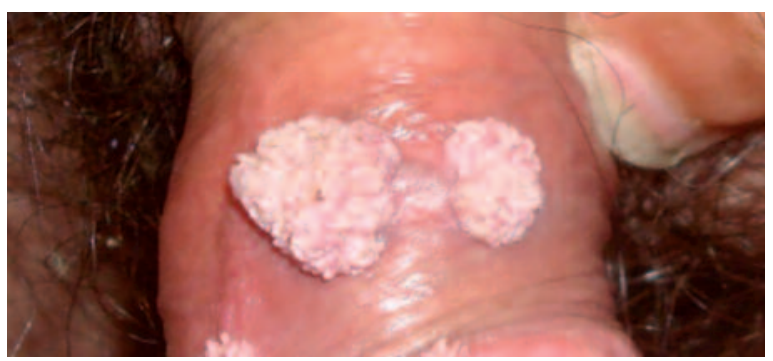

Figura 4. Condiloma acuminado: aspecto de coliflor. 
el beso de la mariposa $\mid$ La piel en la cocina

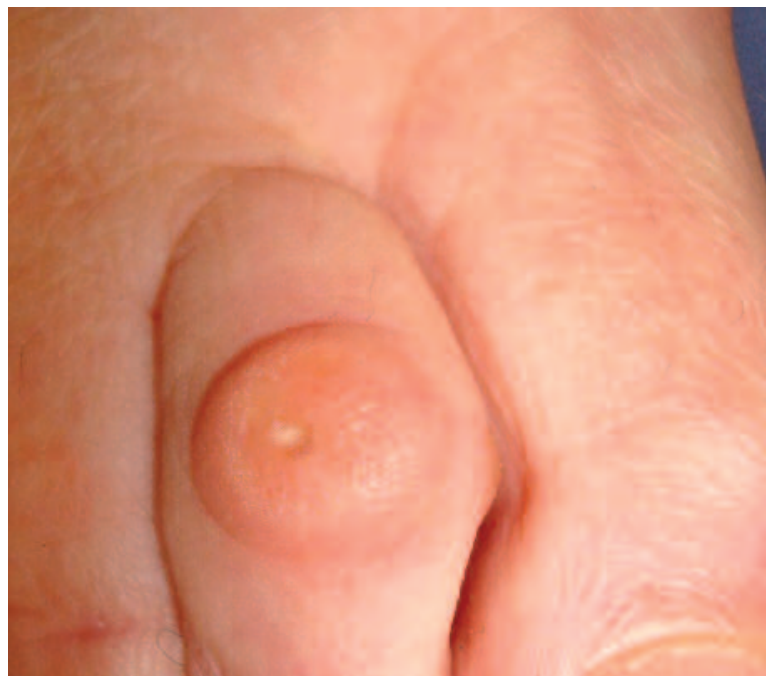

Figura 5. Heloma: lesión en ojo de gallo.

Y si bien es cierto que las enfermedades «cutáneo-culinarias» existen, también les diré que, a menudo, me encuentro con «cabellos de ángel» $\mathrm{y}$ «pieles de melocotón».

Y este sí que es un menú exquisitamente bello.

\section{BIBLIOGRAFÍA}

1. Guerra Tapia A. Don Quijote de la Mancha. Más Dermatol. 2010;10:28-9.

2. Guerra Tapia A. Refranes «al pelo». Más Dermatol. 2010;11: 27-8.

3. Guerra Tapia A. Sissi emperatriz o el abuso de la belleza. Anorexia, bulimia, vigorexia y tricocosmetomanía. Más Dermatol. 2010;12:28-9.

4. Guerra Tapia A. La piel de Pablo Neruda. Más Dermatol. 2011;13:27-9.

5. Guerra Tapia A. El cine y la dermatología psiquiátrica. Stigmata. Más Dermatol. 2011;14:28-9.

6. Guerra Tapia A. Plantas medicinales: el veneno está en la dosis. Más Dermatol. 2011;15:27-9.

7. Guerra Tapia A. La cantante calva y otras mujeres. Más Dermatol. 2012;16:26-8.

8. Guerra Tapia A. Franz Peter Schubert y el estigma de la sífilis. Más Dermatol. 2012;17:28-9.

9. Guerra Tapia A. Las fallas de Valencia y la dermatología. Más Dermatol. 2012;18:27-8.

10. Guerra Tapia A. Pelirrojos y prerrafaelitas. Más Dermatol. 2013;19:28-9.

11. Guerra Tapia A. Mirando al sol. O cuando la fotoprotección no existía. Más Dermatol. 2013;21:31-3.

12. Guerra Tapia A. El mito de Narciso y la Dermatología Estética. Más Dermatol. 2014;22:29-31.

13. Guerra Tapia A. Rosa, rosae. Jugando con las palabras. Más Dermatol. 2014;23:25-27.

14. Guerra Tapia A. La novela corta y la medicina: ideas delirantes y alopecia. Más Dermatol. 2016;24:26-8. 